\title{
Effect of cerebral protection strategy on outcome of patients with Stanford type A aortic dissection
} Dominik Wiedemann, MD, Alfred Kocher, MD, Marion Dorfmeister, MD, Amit Vadehra,
Stephane Mahr, MD, Günther Laufer, MD, and Marek Ehrlich, MD

Objective: The aim of the present study was to assess the efficacy and mid- to long-term results of different cerebral protection techniques in the treatment of acute type A aortic dissection.

Methods: Between April 1987 and January 2011, 329 patients (220 male patients; median age, 60 years; range, 16-87) with type A aortic dissection underwent replacement of the ascending aorta or aortic arch with an open distal anastomosis. Either hypothermic circulatory arrest alone at $18^{\circ} \mathrm{C}(\mathrm{n}=116 ; 35 \%)$ or combined with retrograde cerebral perfusion $(n=122 ; 37 \%)$ or antegrade cerebral perfusion at $25^{\circ} \mathrm{C}(\mathrm{n}=91 ; 28 \%)$ was used.

Results: The median circulatory arrest time was 30 minutes (range, 12-92). The overall 30-day mortality was $19 \%$ (62 of 329). The 30-day mortality stratified by group was $26 \%$ (30 patients) in the hypothermic circulatory arrest group, $16 \%$ in the retrograde cerebral perfusion group (20 patients), and $13 \%$ (12 patients) in the antegrade cerebral perfusion group $(P=.047)$. Permanent neurologic dysfunction occurred in 53 patients $(16 \%)$, with statistically significant differences among the 3 groups $(23 \%$ for hypothermic circulatory arrest, $12 \%$ for retrograde cerebral perfusion, and $12 \%$ for antegrade cerebral perfusion; $P=.033$ ). Univariate analysis showed a significant effect of the brain protection strategy on 30-day mortality and neurologic outcome. Multivariate analysis revealed preoperative hemodynamic instability, preoperative resuscitation, age, and operative year as independent predictors of 30-day mortality. Regarding permanent neurologic dysfunction, the multivariate analysis could not identify any independent predictors. Kaplan-Meier analyses revealed statistically significant differences among the 3 groups with a 1-, 3-, and 5-year survival rate of $84 \%, 79 \%$, and $77 \%$ with antegrade cerebral perfusion, $75 \%, 72 \%$, and $66 \%$ with retrograde cerebral perfusion, and $66 \%, 62 \%$, and $60 \%$ with hypothermic circulatory arrest alone.

Conclusions: Patients in the antegrade cerebral perfusion group had the best short- and long-term survival rates. However, during the study period, several significant improvements in the treatment of patients with type A aortic dissection were achieved; therefore, independent predictors of mortality and permanent neurologic dysfunction were difficult to identify. (J Thorac Cardiovasc Surg 2013;146:647-55)

\section{Supplemental material is available online.}

Acute aortic dissection type $\mathrm{A}$ is a devastating event associated with major morbidity and mortality requiring immediate surgical repair. The goal of surgical intervention is operative survival. To achieve this, the only causative option for patients with acute aortic dissection is replacement of the dissected ascending aorta to prevent myocardial

\footnotetext{
From the Department of Cardiac Surgery, Vienna Medical University, Vienna, Austria.

Disclosures: Authors have nothing to disclose with regard to commercial support.

Presented at the American Heart Association Scientific Meeting, November 2011, Orlando, Fla.

Received for publication April 19, 2012; revisions received June 17, 2012; accepted

for publication July 26, 2012; available ahead of print Aug 27, 2012.

Address for reprints: Dominik Wiedemann, MD, Department of Cardiac Surgery,

Vienna Medical University, Währinger Gürtel 18-20, Vienna 1090, Austria

(E-mail: dominik.wiedemann@meduniwien.ac.at).

$0022-5223 / \$ 36.00$

Copyright (c) 2013 by The American Association for Thoracic Surgery

http://dx.doi.org/10.1016/j.jtcvs.2012.07.072
}

ischemia and cardiac tamponade. The International Registry of Acute Aortic Dissection data reported an in-hospital mortality rate of $26 \%$ in the current era. ${ }^{1}$ Cerebral protection during surgery is crucial for postoperative survival and positive neurologic outcomes. ${ }^{2-4}$ During the past decades, various cerebral protection methods have been used. They have all been based on hypothermic circulatory arrest (HCA), which was introduced clinically by Griepp and colleagues ${ }^{5}$ in 1975 . In addition to HCA alone, cerebral perfusion strategies have been developed to prolong the safe duration of circulatory arrest. In 1986, selective antegrade perfusion of the brain with cold blood during surgery of the aortic arch was introduced by Bachet and colleagues. ${ }^{6}$ Retrograde cerebral perfusion (RCP) was first used in dissection patients by Ueda and colleagues. ${ }^{7}$ These techniques have been described in numerous published studies and have been widely used; however, data from large clinical trials are scarce. ${ }^{8}$

The present study was undertaken to compare the experience and results in patients undergoing surgery for acute type A dissection with 3 different cerebral protection methods at a single center. Particular emphasis was placed 


\section{Abbreviations and Acronyms \\ $\mathrm{ACP}=$ antegrade cerebral perfusion \\ $\mathrm{bACP}=$ bilateral ACP \\ $\mathrm{CPB}=$ cardiopulmonary bypass \\ $\mathrm{HCA}=$ hypothermic circulatory arrest \\ PND = permanent neurologic deficit \\ $\mathrm{RCP}=$ retrograde cerebral perfusion \\ $\mathrm{uACP}=$ unilateral $\mathrm{ACP}$}

on mortality, both in-hospital and long-term, and neurologic outcome.

\section{PATIENTS AND METHODS}

The data from 329 patients with acute aortic dissection type A undergoing replacement of the ascending aorta or aortic arch with an open distal anastomosis at a single center (Department of Cardiac Surgery, Vienna Medical University) between April 1987 and January 2011 were prospectively collected and retrospectively analyzed. The demographic data are listed in Table 1.

\section{Study Groups}

The patients were categorized according to the cerebral protection method used into 1 of 3 groups: HCA alone $(n=116 ; 35 \%)$, HCA combined with RCP $(\mathrm{n}=122 ; 37 \%)$, and HCA combined with antegrade cerebral perfusion (ACP; $n=91 ; 28 \%$; Figure 1 ). The type of cerebral protection was at the surgeon's discretion for the whole study period.

\section{Definitions}

All cases of hemiplegia and paraplegia and every other neurologic deficit resulting from either central or peripheral neurologic damage that was still present at discharge from the hospital was defined as a permanent neurologic deficit (PND). Liver failure was defined as a significant increase in transaminases and an increase in prothrombin time of at least $10 \%$. Near infrared spectroscopy was introduced as a neuromonitoring tool in 1998. Since then, it was used in 150 patients.

\section{Operative Technique}

All operations were performed by way of a median sternotomy. After patients had received heparin (330 IU/kg body weight), cardiopulmonary bypass (CPB) was established through either the femoral artery or right subclavian artery and the right atrium. In cases of tamponade, the strategy was chosen according to patient stability. In hemodynamically stable patients with beginning tamponade, CPB was established before sternotomy. In the case of hemodynamic instability and cardiac tamponade, sternotomy was performed before cannulation, and the heart was decompressed by a small incision into the pericardium.

Once CPB had been established, systemic cooling was immediately initiated. A left ventricular vent was placed through the right superior pulmonary vein, and a retrograde cardioplegia catheter was placed into the coronary sinus. For central neurologic protection, the patient's head was packed in ice bags, and $1000 \mathrm{mg}$ of methylprednisolone was given before the onset of HCA. The ascending aorta was replaced with an open distal anastomosis, if the entry tear or acute type A dissection was located in the aortic root or aortic arch. Surgical therapy also included repair or replacement of the involved structures, such as the aortic valve, aortic root, and/or aortic arch. For HCA and RCP, CPB was stopped after the patient was cooled to the target esophageal temperature of $18^{\circ} \mathrm{C}$. In the case of ACP, circulatory arrest was initiated at an esophageal temperature of $25^{\circ} \mathrm{C}$.

Two different strategies were used to establish ACP. In the case of subclavian artery cannulation for CPB, we snared all supra-aortic arch vessels, including the brachiocephalic trunk, after securing adequate backflow. In the case of femoral artery cannulation for $\mathrm{CPB}$, we inserted a cannula under direct vision into the brachiocephalic trunk, and snared the vessel afterward. In the case of bilateral ACP, the left carotid artery was selectively intubated and perfused after opening the arch. The brain was perfused with blood at a temperature of $25^{\circ} \mathrm{C}$, with a flow rate of $10 \mathrm{~mL} / \mathrm{kg} / \mathrm{min}$ body weight. The lower body was kept in circulatory arrest. In the case of $\mathrm{RCP}$, a 28F cannula was advanced into the superior vena cava, snared cranially of the azygos vein, and connected to the arterial line. Retrograde flow was slowly increased and regulated to achieve a target central venous pressure of $20 \mathrm{~mm} \mathrm{Hg}$. Maintenance of adequate retrograde flow volume required infusion of 500 to $1000 \mathrm{~mL}$. This resulted in a median flow rate of $280 \mathrm{~mL} / \mathrm{min}$ (range, $50-650$ ).

\section{Statistical Analysis}

The data from the patients were analyzed using SPSS statistical software (PASW, version 18.0, for Macintosh; IBM Corp, Somers, NY). Categorical variables are presented as numbers and percentages and continuous variables as medians and ranges. For comparison of continuous variable, we used 1-way analysis of variance testing when 3 groups were compared and the Mann-Whitney $U$ test when 2 groups were compared. Categorical variables were compared using the $\chi^{2}$ test. Survival was compared using Kaplan-Meier analysis and log-rank testing. The most important factors influencing 30-day mortality and PND rates were entered in a binary regression model.

\section{RESULTS \\ Demographic Data}

The 3 groups did not differ significantly with respect to gender, preoperative neurologic deficit (including transient ischemic attack, prolonged reversible ischemic neurologic deficit, and stroke), coronary artery disease, myocardial infarction, previous cardiac surgery, cardiopulmonary resuscitation, and renal failure.

Rupture, hemodynamic instability, arterial hypertension, and pulmonary dysfunction were found more frequently in the HCA only and RCP groups. The RCP patients were significantly younger at surgery (Table 1).

\section{Mortality and Neurologic Outcome}

The overall 30-day mortality was 19\% (62 of 329), with statistically significant differences among the different cerebral protection methods during circulatory arrest. The mortality was $26 \%$ in the HCA group (30/116), $16 \%$ in the HCA plus RCP group (20/122), and $13 \%$ (12/91) in the HCA plus ACP group $(P=.047)$.

The predominant cause of death within 30 days was cardiac failure $(\mathrm{n}=24)$ followed by multiorgan failure $(n=14)$, bleeding episodes $(n=9)$, neurologic complications $(\mathrm{n}=7)$, sepsis $(\mathrm{n}=5)$, and pulmonary failure $(n=2)$. In 1 patient, the cause of death was unknown (see Table E1). 
TABLE 1. Demographic data

\begin{tabular}{|c|c|c|c|c|c|}
\hline Variable & Overall & HCA only & RCP & ACP & $P$ value \\
\hline Patients (n) & 329 & 116 & 122 & 91 & \\
\hline Age at surgery (y) & $60(16-87)$ & $60(16-84)$ & $56(18-87)$ & $62(33-85)$ & .043 \\
\hline Male gender & $220(67 \%)$ & $82(71 \%)$ & $75(62 \%)$ & $63(69 \%)$ & .273 \\
\hline Preoperative PRIND & $2(1 \%)$ & $1(1 \%)$ & 0 & $1(1 \%)$ & .530 \\
\hline Preoperative TIA & $11(3 \%)$ & $4(3 \%)$ & $6(5 \%)$ & $1(1 \%)$ & .320 \\
\hline Preoperative stroke & $7(2 \%)$ & $3(3 \%)$ & $3(3 \%)$ & $1(1 \%)$ & .730 \\
\hline Hemodynamic instability & $60(18 \%)$ & $28(24 \%)$ & $25(21 \%)$ & $7(8 \%)$ & .014 \\
\hline Rupture & $147(45 \%)$ & $55(47 \%)$ & $69(57 \%)$ & $23(25 \%)$ & $<.001$ \\
\hline Cardiopulmonary resuscitation & $12(4 \%)$ & $5(4 \%)$ & $6(5 \%)$ & $1(1 \%)$ & .674 \\
\hline Pulmonary dysfunction & $70(21 \%)$ & $29(25 \%)$ & $33(27 \%)$ & $8(9 \%)$ & .003 \\
\hline Myocardial infarction & $18(6 \%)$ & $4(3 \%)$ & $9(7 \%)$ & $5(6 \%)$ & .413 \\
\hline Coronary artery disease & $49(15 \%)$ & $19(16 \%)$ & $20(16 \%)$ & $10(11 \%)$ & .481 \\
\hline Arterial hypertension & $279(85 \%)$ & $104(90 \%)$ & $107(88 \%)$ & $68(74 \%)$ & .011 \\
\hline Renal failure & $23(7 \%)$ & $6(5 \%)$ & $10(8 \%)$ & $7(8 \%)$ & .618 \\
\hline Previous cardiac surgery & $19(6 \%)$ & $7(6 \%)$ & $7(6 \%)$ & $5(6 \%)$ & .986 \\
\hline
\end{tabular}

Data presented as median (range) or number (\%). HCA, Hypothermic circulatory arrest; RCP, retrograde cerebral perfusion; ACP, antegrade cerebral perfusion; PRIND, prolonged reversible ischemic neurologic deficit; TIA, transient ischemic attack.

Of the 329 patients, 53 (16\%) developed PND: 27 (23\%) in the HCA-only group, $15(12 \%)$ in the RCP group, and 11 $(12 \%)$ in the $\operatorname{ACP}(P=.033$; Tables 2 and 3$)$.

Long-term survival analyses also revealed significant differences among the 3 groups. The survival at $1,3,5$, and 10 years was $66 \%, 62 \%, 60 \%$, and $50 \%$ in the HCA-only group and $75 \%, 72 \%, 66 \%$, and $51 \%$ in the RCP group, respectively; the 1-, 3-, and 5-year survival in the ACP group was $84 \%, 79 \%$, and $77 \%$, respectively (median follow-up, 63 months; range, 1-290; $P=.035$; Figure 2).

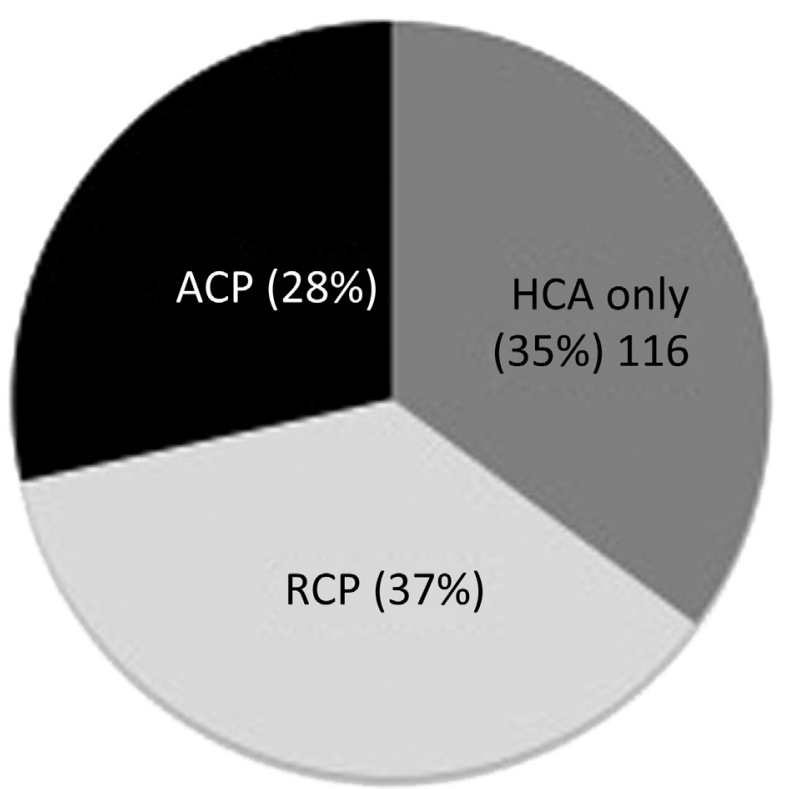

FIGURE 1. Percentage of use for 3 different cerebral protection strategies: hypothermic circulatory arrest $(H C A)$ only $(\mathrm{n}=116)$, retrograde cerebral perfusion $(R C P)(\mathrm{n}=122)$, and antegrade cerebral perfusion $(A C P)$ $(\mathrm{n}=91)$.

\section{Unilateral Versus Bilateral ACP}

In $53(58 \%)$ of the $91 \mathrm{ACP}$ patients, cerebral perfusion was performed unilaterally (uACP) and in $38(42 \%)$, bilaterally (bACP; Figure 3). A subgroup analysis between those 2 groups was performed. The 30-day mortality for the uACP patients was $19 \%$ (10 of 53) and was $5 \%$ (2 of 38) for the bACP patients $(P=.059)$. The circulatory arrest time was slightly longer for the bACP group (29 minutes, range, 11-74; vs 33 minutes, range, 15-113; $P=.023)$. The PND rates were comparable in both groups (uACP, 7 [14\%]; and bACP, $4[11 \%] ; P=.699$ ). The incidence of postoperative renal failure rate (requiring dialysis) was greater in the bACP group than in the uACP group $(12[32 \%]$ vs $5[9 \%]$, respectively; $P=.0173$; Table 4).

Kaplan-Meier analysis revealed no significant differences in long-term survival between the bACP and uACP groups $(1-, 3-$, and 5-year survival rate, $90 \%, 81 \%$, and $73 \%$ vs $79 \%, 77 \%$, and $77 \%$, respectively; $P=.885$ ). The median follow-up was 43 months (range, 1-108; Figure 4).

\section{Risk Factors for Perioperative Mortality}

A comparison of the data from the patients who survived 30 days postoperatively and those who died revealed that the nonsurvivors were significantly older (median age, 65 years; range, 32-84; vs 59 years; range, 16-87; $P=.023)$, were more frequently hemodynamically unstable preoperatively ( $44 \%$ vs $12 \%, P<.001)$, required resuscitation more often $(16 \%$ vs $1 \%, P<.001)$, and had a significantly greater rate of aortic rupture $(58 \%$ vs $42 \%, P=.019)$. The CPB time, aortic crossclamp time, and length of circulatory arrest were slightly longer among the nonsurvivors. Finally, HCA only was used more frequently in nonsurvivors ( $32 \%$ vs $48 \% ; P=.016)$, with 
TABLE 2. Intraoperative data

\begin{tabular}{|c|c|c|c|c|c|}
\hline Variable & Overall & HCA only & RCP & ACP & $P$ value \\
\hline Patients (n) & 329 & 116 & 122 & 91 & \\
\hline CPB time (min) & $180(101-404)$ & $177(101-355)$ & $198(121-404)$ & $161(101-303)$ & $<.01$ \\
\hline Crossclamp time (min) & $109(61-230)$ & $107(61-203)$ & $114(62-230)$ & $109(61-179)$ & $<.037$ \\
\hline Circulatory arrest time (min) & $30(12-92)$ & $36(12-88)$ & $30(14-88)$ & $30(14-92)$ & .993 \\
\hline Cooling time (min) & $56(18-162)$ & $51(26-132)$ & $63(30-162)$ & $47(18-150)$ & $<.01$ \\
\hline Aortic valve surgery & $98(30 \%)$ & $44(38 \%)$ & $33(27 \%)$ & $21(23 \%)$ & .052 \\
\hline David operation & $6(2 \%)$ & $2(2 \%)$ & $2(2 \%)$ & $2(2 \%)$ & .951 \\
\hline Complete arch & $7(2 \%)$ & 0 & $3(3 \%)$ & $4(4 \%)$ & .089 \\
\hline Composite graft & $57(17 \%)$ & $25(22 \%)$ & $19(16 \%)$ & $12(14 \%)$ & .317 \\
\hline "Elephant trunk" & $2(1 \%)$ & $1(1 \%)$ & $1(1 \%)$ & 0 & .680 \\
\hline Stent graft & $22(7 \%)$ & $7(6 \%)$ & $6(5 \%)$ & $9(10 \%)$ & .335 \\
\hline Mitral valve surgery & $3(1 \%)$ & $1(1 \%)$ & $1(1 \%)$ & $1(1 \%)$ & .975 \\
\hline CABG & $27(8 \%)$ & $11(10 \%)$ & $10(8 \%)$ & $6(6 \%)$ & .754 \\
\hline Reoperation & $94(29 \%)$ & $29(25 \%)$ & $44(36 \%)$ & $21(23 \%)$ & .083 \\
\hline
\end{tabular}

Data presented as median (range) or number (\%). $H C A$, Hypothermic circulatory arrest; $R C P$, retrograde cerebral perfusion; $A C P$, antegrade cerebral perfusion; $C P B$, cardiopulmonary bypass; $C A B G$, coronary artery bypass grafting.

only $19 \%$ receiving ACP compared with $30 \%$ of survivors $(P=.069$; Table 5).

Multivariate analyses revealed preoperative hemodynamic instability, cardiopulmonary resuscitation, patient age at surgery, and operative year as independent predictors of 30-day mortality (Table 6). The operative year reached significance $(P=.048)$ but only with a regression coefficient of -0.074 and an odds ratio of 0.929 .

\section{Risk Factors for PND}

No significant demographic differences were found among patients with a PND. In patients with PND, HCA only had been used more frequently $(51 \%$ vs $32 \%$, $P=.008)$. Also, more patients with a PND required surgical revision $(45 \%$ vs $25 \% . P=.006$; Table 7$)$. In the multivariate regression model, adding the operative year as a continuous variable removed every significant influence of any factor; thus, not HCA nor previous cardiac surgery nor operative year was an independent factor in our analysis (Table 8).

\section{Developments in Type A Aortic Dissection Treatment}

The study period was 24 years from April 1987 to January 2011, and, in addition to ACP and RCP, a number of other significant improvements were achieved, including earlier and better diagnosis, a quicker referral to surgery, and better anesthetic management. We stratified the patients according to the era of surgery for type A aortic dissection into 3 groups: 1987 to 1996 (period 1), 1997 to 2004 (period 2), and 2005 to 2011 (period 3). These periods were selected according to the introduction of new techniques, with a certain overlap. A comparison of the pre- and intraoperative patient characteristics showed that the rates of preoperative hemodynamic instability ( $22 \%$ vs $21 \%$ vs $9 \%, P=.052)$ and aortic rupture $(43 \%$ vs $58 \%$ vs $22 \%, P<.001)$ decreased significantly

TABLE 3. Postoperative data

\begin{tabular}{|c|c|c|c|c|c|}
\hline Variable & Overall & HCA only & RCP & ACP & $P$ value \\
\hline Patients (n) & 329 & 116 & 122 & 91 & \\
\hline 30-d Mortality & $62(19 \%)$ & $30(26 \%)$ & $20(16 \%)$ & $12(13 \%)$ & .047. \\
\hline Ventilation time (d) & $3(1-79)$ & $3(1-54)$ & $4(1-79)$ & $2(1-45)$ & .168 \\
\hline ICU stay $(\mathrm{h})$ & $6(1-86)$ & $5(1-73)$ & $7(1-86)$ & $5(1-62)$ & .041 \\
\hline PND & $53(16 \%)$ & $27(23 \%)$ & $15(12 \%)$ & $11(12 \%)$ & .033 \\
\hline TIA & $3(1 \%)$ & $1(1 \%)$ & 0 & $2(2 \%)$ & .253 \\
\hline Liver failure & $8(2 \%)$ & $5(4 \%)$ & $3(3 \%)$ & 0 & .130 \\
\hline Renal failure (requiring dialysis) & $53(16 \%)$ & $20(17 \%)$ & $16(13 \%)$ & $17(19 \%)$ & .454 \\
\hline Multiorgan failure & $25(8 \%)$ & $11(10 \%)$ & $13(11 \%)$ & $1(1 \%)$ & .023 \\
\hline Reintubation & $23(7 \%)$ & $9(8 \%)$ & $12(10 \%)$ & $2(2 \%)$ & .866 \\
\hline Sepsis & $39(12 \%)$ & $23(20 \%)$ & $12(10 \%)$ & $4(4 \%)$ & .002 \\
\hline Hospital stay (d) & $19(3-96)$ & $19(5-77)$ & $20(5-96)$ & $17(3-88)$ & .522 \\
\hline
\end{tabular}

Data presented as number (\%) or median (range). $H C A$, Hypothermic circulatory arrest; $R C P$, retrograde cerebral perfusion; $A C P$, antegrade cerebral perfusion; $I C U$, intensive care unit; $P N D$, permanent neurologic deficit; TIA, transient ischemic attack. 


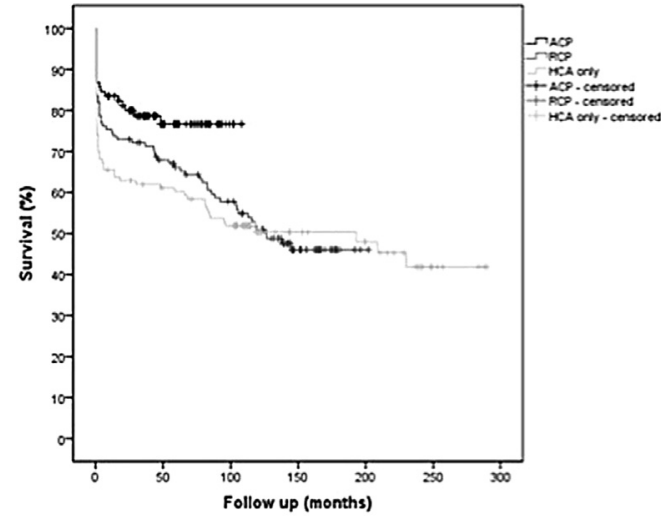

Survival rates:

\begin{tabular}{|l|l|l|l|l|}
\hline & 1 -years & 3 -years & 5 -years & 10 -years \\
\hline HCA only & $66 \%$ & $62 \%$ & $60 \%$ & $50 \%$ \\
\hline RCP & $75 \%$ & $72 \%$ & $66 \%$ & $51 \%$ \\
\hline ACP & $84 \%$ & $79 \%$ & $77 \%$ & n.a. \\
\hline
\end{tabular}

\begin{tabular}{|l|l|l|l|l|}
\hline & 1 -years & 3-years & 5-years & 10 -years \\
\hline HCA only & 75 & 69 & 66 & 30 \\
\hline RCP & 91 & 85 & 73 & 51 \\
\hline ACP & 73 & 52 & 39 & n.a. \\
\hline
\end{tabular}

FIGURE 2. Kaplan-Meier survival analysis curves for antegrade cerebral perfusion $(A C P)$ versus retrograde cerebral perfusion $(R C P)$ versus hypothermic circulatory arrest $(H C A)$ only (log rank, $P=.035$; median follow-up, 63 months; range, 1-290).

during the study period, especially for the last group (Table 9). Although this difference was statistically significant in the case of aortic rupture, it did not reach significance for hemodynamic instability. The rate of preoperative cardiopulmonary resuscitation remained the same for all 3 periods. A comparison of the cerebral protection strategies revealed HCA only as the main strategy for period $1(74 \%)$, with $26 \%$ receiving RCP. During period 2, RCP was the dominant strategy $(56 \%)$, with HCA only decreasing to $27 \%$ and ACP, which was not known in period 1, emerging as a new treatment modality $(16 \%)$. In period 3 , ACP had become the method of choice $(76 \%)$, with HCA only $(11 \%)$ and RCP $(13 \%)$ used only occasionally $(P<.001)$.

Both mortality and the incidence of PND decreased significantly during the study period. The 30-day mortality was $31 \%$ in period $1,16 \%$ in period 2 , and $11 \%$ in period $3(P=.001)$. The corresponding PND rates were $27 \%, 13 \%$, and $11 \%(P=.007)$. Kaplan-Meier analysis revealed a 1-, 3-, 5-, and 10-year survival rate of $56 \%, 51 \%, 49 \%$, and $34 \%$ in period 1 compared with $77 \%, 73 \%, 70 \%$, and $59 \%$ in period 2 , respectively. By contrast, the 1-, 3-, and 5-year survival

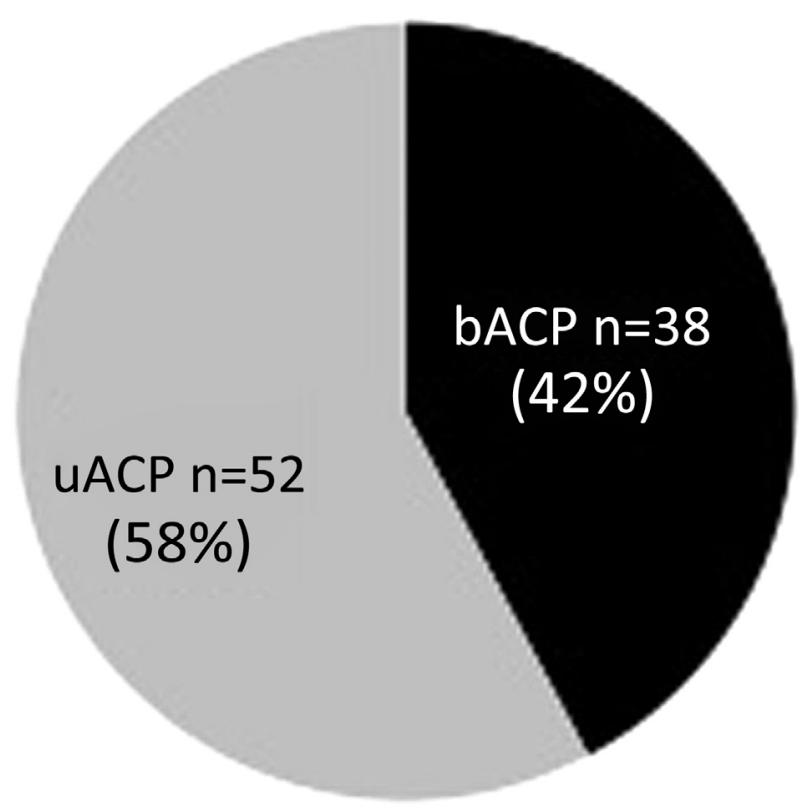

FIGURE 3. Percentage of patients in antegrade cerebral perfusion $(A C P)$ group perfused either unilaterally $(u A C P)$ or bilaterally $(b A C P)$.

rate in period 3 was $87 \%, 85 \%$, and $82 \%$, respectively $(P<.001$; Figure 5).

\section{DISCUSSION}

Taken together, our data indicate that the outcome of surgical treatment of type A dissection at our center has improved over time and that ACP at hypothermic circulatory arrest yields the best results with regard to mortality and PND.

Acute dissection of the aorta was first described in detail in 1760 when King George II died of this condition. ${ }^{9}$ It is a catastrophic event that represents a formidable surgical challenge. Without surgery, $50 \%$ of patients die within the first 48 hours, and the 2 -week mortality rate approaches $80 \%$ in patients with undiagnosed or untreated ascending aortic dissection. ${ }^{1,10,11}$ With improved preoperative diagnosis, better prosthetic material, amelioration of cardiac and cerebral protection, and increased surgical experience, the results have improved during the past 20 years. ${ }^{12,13}$ However, the average mortality in most registries remains $20 \%$ to $25 \%$. $^{2,14,15}$

Surgical treatment of type A aortic dissection consists primarily of replacement of the ascending aorta to exclude the entry tear and prevent expansion of the dissection toward the aortic root and rupture into the pericardial sac. In about $10 \%$ of patients, the aortic root is involved, and $5 \%$ of the patients require replacement of the entire aortic arch. Deep HCA is the most commonly used method of cerebral protection during surgery of the aortic arch. However, this technique offers only a limited period for arch repair. Also, it requires prolonged $\mathrm{CPB}$ to rewarm the patient, 
TABLE 4. Subgroup analysis of unilateral ACP vs bilateral ACP

\begin{tabular}{|c|c|c|c|}
\hline Variable & uACP & bACP & $P$ valu \\
\hline Patients (n) & $53(58 \%)$ & $38(42 \%)$ & \\
\hline CPB time (min) & $165(101-303)$ & $157(102-285)$ & .243 \\
\hline Aortic crossclamp time (min) & $109(62-166)$ & $95(61-179)$ & .717 \\
\hline Circulatory arrest time (min) & $32(15-88)$ & $29(12-74)$ & .152 \\
\hline Cooling time (min) & $47(21-120)$ & $45(18-150)$ & .218 \\
\hline Aortic valve surgery & $12(23 \%)$ & $9(24 \%)$ & .946 \\
\hline David operation & $2(4 \%)$ & 0 & .226 \\
\hline Complete arch & $1(2 \%)$ & $3(8 \%)$ & .168 \\
\hline Composite graft & $10(19 \%)$ & $3(8 \%)$ & .140 \\
\hline "Elephant trunk" & 0 & 0 & \\
\hline Stent graft & $7(13 \%)$ & $2(5 \%)$ & .211 \\
\hline Mitral valve surgery & $1(2 \%)$ & 0 & .395 \\
\hline CABG & $2(4 \%)$ & $4(11 \%)$ & .201 \\
\hline Reoperation & $12(23 \%)$ & $9(24 \%)$ & .986 \\
\hline 30-d Mortality & $10(19 \%)$ & $2(5 \%)$ & .059 \\
\hline Ventilation time $(\mathrm{d})$ & $3(1-45)$ & $1(1-14)$ & .308 \\
\hline ICU stay (h) & $5(1-62)$ & $4(1-55)$ & .308 \\
\hline Hospital stay (d) & $16(3-83)$ & $21(7-88)$ & .346 \\
\hline Transitory psychotic syndrome & $6(11 \%)$ & 0 & .027 \\
\hline PND & $7(14 \%)$ & $4(11 \%)$ & .699 \\
\hline TIA & $1(2 \%)$ & $1(3 \%)$ & .855 \\
\hline $\begin{array}{l}\text { Renal failure } \\
\text { (requiring dialysis) }\end{array}$ & $5(9 \%)$ & $12(32 \%)$ & .013 \\
\hline Multiorgan failure & $1(2 \%)$ & 0 & .376 \\
\hline Reintubation & $1(2 \%)$ & $1(3 \%)$ & .361 \\
\hline Sepsis & $1(2 \%)$ & $3(8 \%)$ & 196 \\
\hline
\end{tabular}

Data presented as number $(\%)$ or median (range). $A C P$, Antegrade cerebral perfusion; $u A C P$, unilateral ACP; $b A C P$, bilateral ACP; $C P B$, cardiopulmonary bypass; $C A B G$, coronary artery bypass grafting; $I C U$, intensive care unit; $P N D$, permanent neurologic deficit; TIA, transient ischemic attack.

and this has been associated with several complications such as severe bleeding and an intense requirement for blood products. $^{5}$

Although these surgical treatment modalities have not changed dramatically during the past 35 years, the development of better cerebral protection methods has been an important focus of aortic surgical research. In 1990, Ueda and colleagues ${ }^{7}$ reported a series of patients with RCP through the superior vena cava during arch exclusion. Coselli and colleagues ${ }^{16}$ reported that the mortality $(7.9 \%)$ and stroke rate $(2.4 \%)$ of patients undergoing aortic surgery with RCP were favorable. These favorable results were confirmed by other small clinical trials, and the technique of RCP became widely adopted. ${ }^{17}$ The technique of ACP had already been described in $1986^{6}$; however, it only became standard in most centers during the past 5 to 10 years. ${ }^{6}$ Although the experience with RCP is now more than 2 decades, controversy still exists about whether RCP has a neuroprotective effect above and beyond that provided by HCA. Some uptake of oxygen during retrograde flow clearly occurs; however, most efforts to document significant improvement in cerebral metabolic function owing to nutritive flow during RCP have failed. Furthermore,

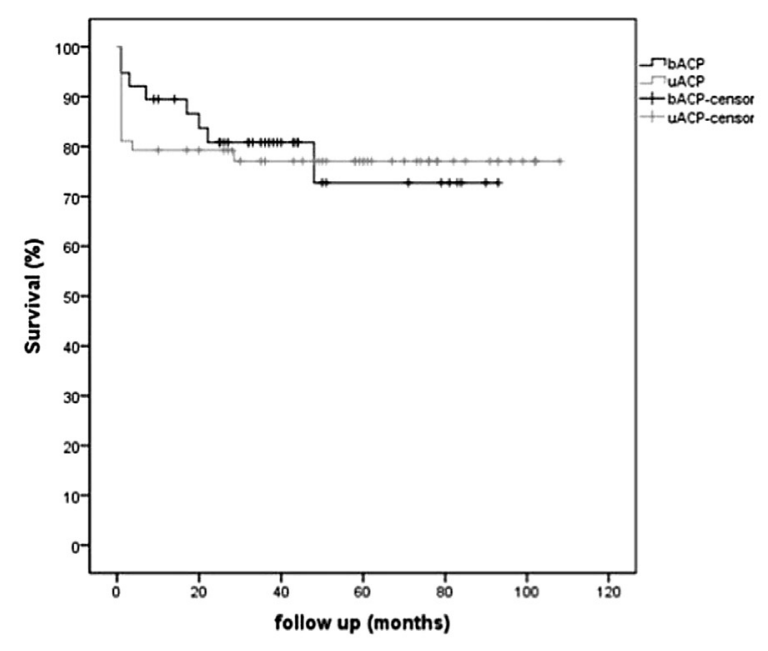

Survival rates:

\begin{tabular}{|l|l|l|l|}
\hline & 1 year & 3 years & 5 years \\
\hline uACP & $79 \%$ & $77 \%$ & $77 \%$ \\
\hline bACP & $90 \%$ & $81 \%$ & $73 \%$ \\
\hline
\end{tabular}

Patients at risk:

\begin{tabular}{|l|l|l|l|}
\hline & 1 year & 3 years & 5 years \\
\hline uACP & 41 & 32 & 22 \\
\hline bACP & 32 & 19 & 7 \\
\hline
\end{tabular}

FIGURE 4. Kaplan-Meier survival analysis curves for unilateral antegrade cerebral perfusion $(u A C P)$ versus bilateral ACP $(b A C P)(\log$ rank, $P=.885$; median follow-up, 43 months; range, 1-108).

experimental studies have shown that significant shunting of blood away from the brain occurs during RCP by way of venovenous anastomoses. ${ }^{17,18}$ The only effect that RCP might have is a positive influence on cooling, which helps to protect the brain, especially in patient with insufficient systemic cooling. Although ACP has became the standard approach for an ever-increasing number of centers worldwide, ${ }^{19}$ no consensus has been reached among cardiac surgeons concerning the optimal strategy and temperature management for cerebral protection during acute aortic dissection type A surgery. The broad range of preoperative conditions, pathologic anatomic features, complications, and surgical procedures in patients with acute aortic dissection type A and the diversity of CPB strategies has hampered comparisons of postoperative outcomes and the available data. ${ }^{8}$ Most publications on this topic have contained data from registries, which have the advantage of including a large number of patients. However, the disadvantage of such registries is that they include data from various centers with several different strategies in operative and anaesthesiologic management. 
TABLE 5. Survivors vs nonsurvivors at 30 days

\begin{tabular}{|c|c|c|c|}
\hline Variable & $\begin{array}{c}\text { 30-d } \\
\text { Survivors }\end{array}$ & $\begin{array}{c}\text { 30-d } \\
\text { Nonsurvivors }\end{array}$ & $\begin{array}{c}P \\
\text { value }\end{array}$ \\
\hline Patients (n) & 267 & 62 & \\
\hline Age at surgery $(y)$ & $59(16-87)$ & $65(32-84)$ & .023 \\
\hline Male gender & $181(68 \%)$ & $39(63 \%)$ & .461 \\
\hline Preoperative PRIND & $2(1 \%)$ & 0 & .494 \\
\hline Preoperative TIA & $10(4 \%)$ & $1(2 \%)$ & .405 \\
\hline Preoperative stroke & $7(3 \%)$ & 0 & .198 \\
\hline Hemodynamic instability & $33(12 \%)$ & $27(44 \%)$ & $<.001$ \\
\hline Rupture & $111(42 \%)$ & $36(58 \%)$ & .019 \\
\hline CPR & $2(1 \%)$ & $10(16 \%)$ & $<.001$ \\
\hline Intubated & $53(20 \%)$ & $17(27 \%)$ & .172 \\
\hline Myocardial infarction & $16(6 \%)$ & $2(3 \%)$ & .398 \\
\hline Coronary artery disease & $37(14 \%)$ & $12(20 \%)$ & .173 \\
\hline Arterial hypertension & $226(85 \%)$ & $53(87 \%)$ & .658 \\
\hline Renal failure & $19(7 \%)$ & $4(7 \%)$ & .872 \\
\hline Previous cardiac surgery & $12(5 \%)$ & $7(11 \%)$ & .051 \\
\hline CPB time (min) & $179(101-316)$ & $198(103-404)$ & .001 \\
\hline Aortic crossclamp time (min) & $108(61-230)$ & $118(67-199)$ & .021 \\
\hline Circulatory arrest time (min) & $29(15-92)$ & $34(14-88)$ & .037 \\
\hline Cooling time (min) & $55(18-162)$ & $57(28-132)$ & .341 \\
\hline Aortic valve surgery & $76(29 \%)$ & $22(36 \%)$ & .284 \\
\hline David operation & $6(2 \%)$ & 0 & .234 \\
\hline Complete arch & $5(2 \%)$ & $2(3 \%)$ & .506 \\
\hline Composite graft & $40(15 \%)$ & $17(27 \%)$ & .020 \\
\hline "Elephant trunk" & $2(1 \%)$ & 0 & .648 \\
\hline Stent graft & $20(8 \%)$ & $2(3 \%)$ & .226 \\
\hline CABG & $18(7 \%)$ & $9(15 \%)$ & .045 \\
\hline Reoperation & $73(28 \%)$ & $20(32 \%)$ & .130 \\
\hline HCA only & $86(32 \%)$ & $30(48 \%)$ & .016 \\
\hline $\mathrm{RCP}$ & $102(38 \%)$ & $20(32 \%)$ & .383 \\
\hline $\mathrm{ACP}$ & $79(30 \%)$ & $12(19 \%)$ & .069 \\
\hline
\end{tabular}

Data presented as median (range) or number (\%). PRIND, Prolonged reversible ischemic neurologic deficit; TIA, transient ischemic attack; $C P R$, cardiopulmonary resuscitation; $C P B$, cardiopulmonary bypass; $C A B G$, coronary artery bypass grafting; $H C A$, hypothermic circulatory arrest; $R C P$, retrograde cerebral perfusion; $A C P$, antegrade cerebral perfusion.

In the present study, the overall 30-day mortality rate was $19 \%$, similar to that in recent reported studies. ${ }^{20,21} \mathrm{In}$ hospital mortality was greater among patients in whom HCA only was used $(26 \%)$, followed by the RCP group $(16 \%)$ and $13 \%$ in the ACP group. The same was true for

TABLE 6. Multivariate analysis for 30-day mortality

\begin{tabular}{lccccc}
\hline \multicolumn{1}{c}{ Variable } & Wald & $\boldsymbol{P}$ value & OR & $\begin{array}{c}\text { Regression } \\
\text { coefficient }\end{array}$ & $\mathbf{9 5 \%} \mathbf{C I}$ \\
\hline Age & 4.828 & .028 & 1.026 & 0.026 & $1.003-1.051$ \\
HCA only & 1.321 & .250 & 1.539 & 0.431 & $0.738-3.213$ \\
ACP & 0.321 & .571 & 1.354 & 0.303 & $0.475-3.862$ \\
Hemodynamic & 8.970 & .003 & 3.073 & 1.123 & $1.474-6.407$ \\
$\quad$ instability & & & & & \\
CPR & 8.732 & .003 & 12.838 & 2.552 & $2.362-69.778$ \\
Operative year & 3.917 & .048 & 0.929 & -0.074 & $0.863-0.999$ \\
\hline OR Od7
\end{tabular}

$O R$, Odds ratio; $C I$, confidence interval; $H C A$, hypothermic circulatory arrest; $A C P$, antegrade cerebral perfusion; $C P R$, cardiopulmonary resuscitation.
TABLE 7. Permanent neurologic deficit vs none

\begin{tabular}{|c|c|c|c|}
\hline \multirow[b]{2}{*}{ Variable } & \multicolumn{2}{|c|}{ PND } & \multirow[b]{2}{*}{$P$ value } \\
\hline & Yes & No & \\
\hline Patients (n) & $53(16 \%)$ & $276(84 \%)$ & \\
\hline Age at surgery $(y)$ & $64(31-87)$ & $59(16-85)$ & 178 \\
\hline Male gender & $37(70 \%)$ & $183(66 \%)$ & .372 \\
\hline Preoperative PRIND & 0 & $2(1 \%)$ & .710 \\
\hline Preoperative TIA & $2(4 \%)$ & $9(3 \%)$ & .535 \\
\hline Preoperative stroke & $2(4 \%)$ & $5(2 \%)$ & .304 \\
\hline Hemodynamic instability & $14(26 \%)$ & $46(16 \%)$ & .156 \\
\hline Rupture & $29(55 \%)$ & $118(43 \%)$ & .073 \\
\hline $\mathrm{CPR}$ & $4(8 \%)$ & $8(3 \%)$ & .1 \\
\hline Intubated & $15(28 \%)$ & $55(20 \%)$ & .125 \\
\hline Myocardial infarction & $4(8 \%)$ & $14(5 \%)$ & .316 \\
\hline Coronary artery disease & $11(21 \%)$ & $38(14 \%)$ & .142 \\
\hline Arterial hypertension & $47(89 \%)$ & $232(84 \%)$ & .283 \\
\hline Renal failure & $1(2 \%)$ & $22(8 \%)$ & .091 \\
\hline Previous cardiac surgery & $2(4 \%)$ & $17(6 \%)$ & .378 \\
\hline CPB time (min) & $179(101-304)$ & $180(101-404)$ & .704 \\
\hline Aortic crossclamp time (min) & $107(62-205)$ & $110(61-230)$ & .455 \\
\hline Circulatory arrest time (min) & $31(14-72)$ & $30(12-92)$ & .517 \\
\hline Cooling time (min) & $55(28-143)$ & $56(18-162)$ & .572 \\
\hline Aortic valve surgery & $12(23 \%)$ & $86(31 \%)$ & .136 \\
\hline David operation & 0 & $6(2 \%)$ & .345 \\
\hline Complete arch & $3(6 \%)$ & $4(1 \%)$ & .086 \\
\hline Composite graft & $9(17 \%)$ & $48(17 \%)$ & .562 \\
\hline "Elephant trunk" & $2(4 \%)$ & 0 & .026 \\
\hline Stent graft & $2(4 \%)$ & $20(7 \%)$ & .279 \\
\hline Mitral valve surgery & 0 & $3(1 \%)$ & .589 \\
\hline CABG & $6(11 \%)$ & $21(8 \%)$ & .255 \\
\hline Reoperation & $24(45 \%)$ & $70(25 \%)$ & .006 \\
\hline HCA only & $27(51 \%)$ & $89(32 \%)$ & .008 \\
\hline $\mathrm{RCP}$ & $15(28 \%)$ & $107(39 \%)$ & .097 \\
\hline $\mathrm{ACP}$ & $11(21 \%)$ & $80(29 \%)$ & .144 \\
\hline $\mathrm{uACP}$ & $7(13 \%)$ & $45(16 \%)$ & .468 \\
\hline bACP & $4(8 \%)$ & $34(12 \%)$ & .468 \\
\hline Liver failure & $4(8 \%)$ & $4(1 \%)$ & .026 \\
\hline Pulmonary failure & $10(19 \%)$ & $19(7 \%)$ & .010 \\
\hline $\begin{array}{l}\text { Renal failure } \\
\text { (requiring dialysis) }\end{array}$ & $16(30 \%)$ & $37(13 \%)$ & .06 \\
\hline Multiorgan failure & $5(9 \%)$ & $20(7 \%)$ & .409 \\
\hline Sepsis & $15(28 \%)$ & $24(9 \%)$ & $<.001$ \\
\hline
\end{tabular}

Data presented as median (range) or number (\%). PND, Permanent neurologic deficit; PRIND, prolonged reversible ischemic neurologic deficit; TIA, transient ischemic attack; $C P R$, cardiopulmonary resuscitation; $C P B$, cardiopulmonary bypass; $C A B G$, coronary artery bypass grafting; $H C A$, hypothermic circulatory arrest; $R C P$, retrograde cerebral perfusion; $A C P$, antegrade cerebral perfusion; $u A C P$, unilateral $\mathrm{ACP}$; $b A C P$, bilateral ACP.

long-term survival. RCP showed major improvement in reducing mortality and PND but failed to show benefit in avoiding temporary neurologic dysfunction. In contrast, ACP, not only was associated with the lowest hospital mortality and PND, but also showed a benefit in reducing the occurrence of transient postoperative neurologic deficits. Similar results were found by Okita and colleagues ${ }^{22}$ from Japan.

The significantly lower hospital mortality rate and PND using ACP compared with RCP or HCA alone in the present 
TABLE 8. Multivariate analysis for permanent neurologic deficit

\begin{tabular}{lccccc}
\multicolumn{1}{c}{ Variable } & Wald & $\boldsymbol{P}$ value & $\begin{array}{c}\text { Regression } \\
\text { coefficient }\end{array}$ & OR & 95\% CI \\
\hline Age & 2.703 & .100 & 0.019 & 1.019 & $0.996-1.042$ \\
HCA only & 2.143 & .143 & 0.519 & 1.681 & $0.839-3.370$ \\
$\begin{array}{l}\text { Previous cardiac } \\
\quad 0.897\end{array}$ & .343 & -0.745 & 0.475 & $0.102-2.217$ \\
$\quad \begin{array}{l}\text { surgery } \\
\text { Operative year }\end{array}$ & 3.536 & .060 & -0.058 & 0.944 & $0.888-1.002$ \\
\hline
\end{tabular}

$O R$, Odds ratio; $C I$, confidence interval; $H C A$, hypothermic circulatory arrest.

study has shown the superior cerebral protection provided by ACP when prolonged and acute operations on the thoracic aorta are undertaken.

In our study, we not only compared the 3 basic methods of cerebral protection, but also performed a subgroup analysis of bACP versus uACP. Although, basically the outcomes in these 2 groups were not significantly different, there seemed to be at least a trend toward better 30-day survival in the bACP group. Nevertheless, this result could have been biased because during the introduction period of $\mathrm{ACP}$ in our center, we did not use near infrared spectroscopy for continuous neuromonitoring. Therefore, it is possible that a few of the uACP patients showed a decrease in oxygen saturation in the near infrared spectroscopy. In the last years of the study, we have advocated uACP with continuous neuromonitoring, with the possibility of switching to bACP in the case of left hemispheric cerebral malperfusion, as the procedure of choice for cerebral protection in patients undergoing surgery for aortic arch pathologic findings.

Only hemodynamic instability, preoperative cardiopulmonary resuscitation, patient age, and operative year were statistically significant independent risk factors for

TABLE 9. Study periods for type A aortic dissection surgery

\begin{tabular}{lcccr}
\hline \multicolumn{1}{c}{ Variable } & $\begin{array}{c}\text { Period 1 } \\
(\mathbf{1 9 8 7 - 1 9 9 6})\end{array}$ & $\begin{array}{c}\text { Period 2 } \\
(\mathbf{1 9 9 7 - 2 0 0 4})\end{array}$ & $\begin{array}{c}\text { Period 3 } \\
(\mathbf{2 0 0 5}-J a n u a r y ~ 2011)\end{array}$ & $\begin{array}{c}\boldsymbol{P} \\
\text { value }\end{array}$ \\
\hline Patients (n) & 86 & 158 & 85 & \\
Age (y) & $57(16-81)$ & $59(18-87)$ & $62(33-85)$ & .183 \\
Male gender & $59(67 \%)$ & $97(61 \%)$ & $64(75 \%)$ & .083 \\
Preoperative & $19(22 \%)$ & $33(21 \%)$ & $8(9 \%)$ & .052 \\
$\quad$ hemodynamic & & & & \\
$\quad$ instability & & & & \\
CPR & $3(3 \%)$ & $7(4 \%)$ & $2(2 \%)$ & .712 \\
Rupture & $37(43 \%)$ & $91(58 \%)$ & $19(22 \%)$ & $<.001$ \\
PND & $23(27 \%)$ & $21(13 \%)$ & $9(11 \%)$ & .007 \\
30-d Mortality & $27(31 \%)$ & $26(16 \%)$ & $9(11 \%)$ & .001 \\
HCA only & $64(74 \%)$ & $43(27 \%)$ & $9(11 \%)$ & $<.001$ \\
ICU stay & $6(1-86)$ & $6(1-62)$ & $5(1-63)$ & .667 \\
RCP & $22(26 \%)$ & $89(56 \%)$ & $11(13 \%)$ & $<.001$ \\
ACP & 0 & $26(16 \%)$ & $65(76 \%)$ & $<.001$ \\
\hline
\end{tabular}

Data presented as median (range) or number (\%). CPR, Cardiopulmonary resuscitation; $P N D$, permanent neurologic deficit; $H C A$, hypothermic circulatory arrest; $I C U$, intensive care unit; $R C P$, retrograde cerebral perfusion; $A C P$, antegrade cerebral perfusion.

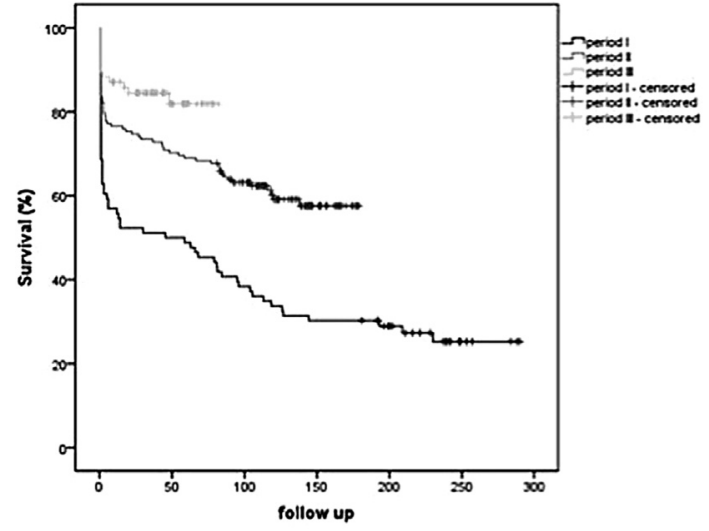

Survival rates

\begin{tabular}{|l|l|l|l|l|}
\hline & $1-$ years & $3-y e a r s$ & 5-years & 10 -years \\
\hline Period I & $56 \%$ & $51 \%$ & $49 \%$ & $34 \%$ \\
\hline Period II & $77 \%$ & $73 \%$ & $70 \%$ & $59 \%$ \\
\hline Period III & $87 \%$ & $85 \%$ & $8 \%$ & n.a. \\
\hline
\end{tabular}

\begin{tabular}{|l|l|l|l|l|}
\hline & 1 -years & 3 -years & 5 -years & 10 -years \\
\hline Period I & 48 & 44 & 42 & 29 \\
\hline Period II & 121 & 116 & 109 & 52 \\
\hline Period III & 70 & 46 & 29 & n.a. \\
\hline
\end{tabular}

FIGURE 5. Survival rates in 3 different eras of aortic surgery (log rank, $P<.001)$.

mortality in our patient population. This was not surprising, and results reported by others would lead to the expectation that patients with frank rupture and hemodynamic compromise would have a worse outcome than patients who were stable preoperatively. Also not surprisingly, older patients with such aortic pathologic findings had worse outcomes than younger patients.

That concomitant procedures failed to have any effect on mortality was also reassuring, suggesting that the current approach at our institution, which involves resecting the site of the intimal tear and performing adjunctive procedures when clinically indicated, is a reasonable method to treat acute dissection in a setting in which aneurysm surgery is a routine procedure. The use of the Bentall-de Bono procedure depended on the degree of aortic valve insuffciency and the judgment of the surgeon of whether a competent valve could be achieved by resuspension. However, various approaches to the aortic valve-leaving it untouched, replacing it, or resuspending the valve leaflets-also had no effect on mortality. It is possible, however, that some aspects of these results might not easily be extrapolated to institutions with less experience with dissection and aneurysms. It must be emphasized that the principal object of emergency surgery for acute dissection must be the immediate survival of the patient, and more limited 
operations could be more appropriate under particular circumstances.

\section{Study Limitations}

The major limitation of the present study was that all data were analyzed retrospectively, a process that mandates caution in the interpretation of the results. Factors such as the "learning curve" of each surgeon during the study period and improvement in intra- and postoperative care cannot be considered in a retrospective study. Particularly because of the long observation period, it was very difficult to identify strong independent predictors of mortality or PND. This limitation was strongly supported by the finding that including the operative year in the multivariate analysis removed every other independent predictor for PND, leaving only age, cardiopulmonary resuscitation, and hemodynamic instability as predictors of mortality. During the past decades, not only have the surgical technique and neuroprotective methods improved, but also better anesthesetic management, earlier and better diagnosis of the disease, accelerated transfer to the operating room, and a higher awareness of the transferring physicians of the disease are factors that have led to significant improvements in the outcomes of patients undergoing surgery for type A aortic dissection.

\section{CONCLUSIONS}

Patients in the ACP group had the best short- and longterm survival in our series. However, owing to the rather long study period, several improvements in the treatment of patients with type A aortic dissection have been achieved. Therefore, it was difficult to identify ACP as favorable predictor. Patients in the HCA-only group had significantly greater rates of PND. However, on multivariate regression analysis, HCA could not be identified as an independent predictor of PND. Finally, 30-day mortality was mainly influenced by the preoperative hemodynamic status, with hemodynamic instability resulting in greater mortality.

\section{References}

1. Tsai TT, Trimarchi S, Nienaber CA. Acute aortic dissection: perspectives from the International Registry of Acute Aortic Dissection (IRAD). Eur J Vasc Endovasc Surg. 2009;37:149-59.

2. Tsukube T, Hayashi T, Kawahira T, Haraguchi T, Matsukawa R, Kozawa S, et al. Neurological outcomes after immediate aortic repair for acute type A aortic dissection complicated by coma. Circulation. 2011;124:S163-7.
3. Ehrlich MP, Schillinger M, Grabenwoger M, Kocher A, Tschernko EM, Simon P, et al. Predictors of adverse outcome and transient neurological dysfunction following surgical treatment of acute type A dissections. Circulation. 2003; 108(Suppl 1):II318-23.

4. Ehrlich MP, Wolner E. Neuroprotection in aortic surgery. Thorac Cardiovasc Surg. 2001;49:247-50.

5. Griepp RB, Stinson EB, Hollingsworth JF, Buehler D. Prosthetic replacement of the aortic arch. J Thorac Cardiovasc Surg. 1975;70:1051-63.

6. Bachet J, Guilmet D, Goudot B, Dreyfus GD, Delentdecker P, Brodaty D, et al. Antegrade cerebral perfusion with cold blood: a 13-year experience. Ann Thorac Surg. 1999;67:1874-8. 1891, 1874.

7. Ueda Y, Miki S, Kusuhara K, Okita Y, Tahata T, Yamanaka K. Surgical treatment of aneurysm or dissection involving the ascending aorta and aortic arch, utilizing circulatory arrest and retrograde cerebral perfusion. J Cardiovasc Surg (Torino). 1990;31:553-8.

8. Kruger T, Weigang E, Hoffmann I, Blettner M, Aebert H. Cerebral protection during surgery for acute aortic dissection type A: results of the German Registry for Acute Aortic Dissection Type A (GERAADA). Circulation. 2011;124: 434-43.

9. Nichols F. Observations concerning the body of His Majesty. Phiosophical Transactions. 1761;52:265-74.

10. Fuster V, Ip JH. Medical aspects of acute aortic dissection. Semin Thorac Cardiovasc Surg. 1991;3:219-24.

11. Anagnostopoulos CE, Prabhakar MJ, Kittle CF. Aortic dissections and dissecting aneurysms. Am J Cardiol. 1972;30:263-73.

12. Easo J, Weigang E, Holzl PP, Horst M, Hoffmann I, Blettner M; GERAADA Study Group. Influence of operative strategy for the aortic arch in DeBakey type I aortic dissection: analysis of the German Registry for Acute Aortic Dissection Type A. J Thorac Cardiovasc Surg. Epub 2011 Nov 16.

13. Ehrlich MP, Ergin MA, McCullough JN, Lansman SL, Galla JD, Bodian CA et al. Results of immediate surgical treatment of all acute type A dissections. Circulation. 2000;102:III248-52.

14. Tanaka M, Kimura N, Yamaguchi A, Adachi H. In-hospital and long-term results of surgery for acute type A aortic dissection: 243 consecutive patients. Ann Thorac Cardiovasc Surg. 2011;18:18-23.

15. Tsai TT, Evangelista A, Nienaber CA, Trimarchi S, Sechtem U, Fattori R, et al. Long-term survival in patients presenting with type A acute aortic dissection: insights from the International Registry of Acute Aortic Dissection (IRAD). Circulation. 2006;114:I350-6.

16. Coselli JS, Crawford ES, Beall AC Jr, Mizrahi EM, Hess KR, Patel VM. Determination of brain temperatures for safe circulatory arrest during cardiovascular operation. Ann Thorac Surg. 1988;45:638-42.

17. Ehrlich MP, Fang WC, Grabenwoger M, Kocher A, Ankersmit J, Laufer G, et al Impact of retrograde cerebral perfusion on aortic arch aneurysm repair. J Thorac Cardiovasc Surg. 1999;118:1026-32.

18. Ehrlich MP, Hagl C, McCullough JN, Zhang N, Shiang H, Bodian C, et al. Retrograde cerebral perfusion provides negligible flow through brain capillaries in the pig. J Thorac Cardiovasc Surg. 2001;122:331-8.

19. Misfeld M, Leontyev S, Borger MA, Gindensperger O, Lehmann S, Legare JF, et al What is the best strategy for brain protection in patients undergoing aortic arch surgery? A single center experience of 636 patients. Ann Thorac Surg. 2012;93:1502-8.

20. Goda M, Imoto K, Suzuki S, Uchida K, Yanagi H, Yasuda S, et al. Risk analysis for hospital mortality in patients with acute type A aortic dissection. Ann Thorac Surg. 2010;90:1246-50.

21. Safi HJ, Brien HW, Winter JN, Thomas AC, Maulsby RL, Doerr HK, et al. Brain protection via cerebral retrograde perfusion during aortic arch aneurysm repair. Ann Thorac Surg. 1993;56:270-6.

22. Okita Y, Minatoya K, Tagusari O, Ando M, Nagatsuka K, Kitamura S Prospective comparative study of brain protection in total aortic arch replacement: deep hypothermic circulatory arrest with retrograde cerebral perfusion or selective antegrade cerebral perfusion. Ann Thorac Surg. 2001;72:72-9. 
TABLE E1. Cause of death (30-day mortality)

\begin{tabular}{lc}
\multicolumn{1}{c}{ Cause of death } & Patients $(\mathbf{n}=\mathbf{6 2})$ \\
\hline Cardiac failure & 24 \\
Multiorgan failure & 14 \\
Bleeding & 9 \\
Neurologic complications & 7 \\
Sepsis & 5 \\
Pulmonary failure & 2 \\
Unknown & 1 \\
\hline
\end{tabular}

